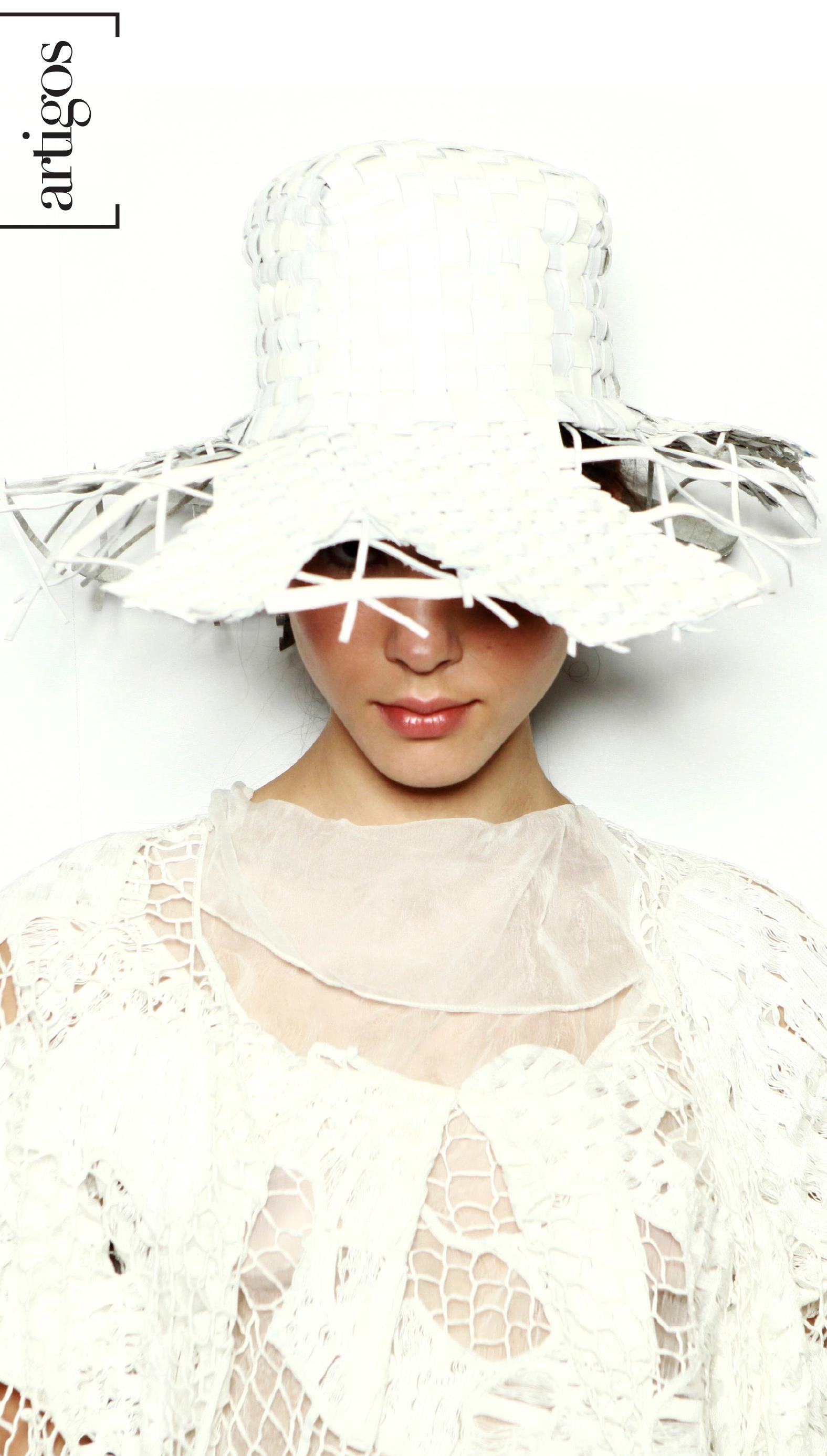


artigo ] voLume 10 | NÚMERO 21 | MAIO 2017

[MARIA EDUARDA ARAUJO GUIMARÃES]

Doutora em Ciências Sociais (Unicamp) e docente do curso de Design

de Moda do Centro Universitário Senac.

E-mail: guimaraes.madu@gmail.com

\section{A moda do futuro ou o futuro da moda?}

\section{Fashion of future or future of fashion?}

[resumo] Este artigo pretende desenvolver uma reflexão sobre os estudos antecipatórios e as metodologias de prospecção de futuro e sua relação com a moda, pensada aqui como meio de expressão de comportamentos e de consumo. Essas metodologias são: a análise de tendências, a construção de cenários e a criação de narrativas. Como parte introdutória desta discussão também analisaremos a relação da moda com o tempo, discutindo as possibilidades de se pensar uma moda do futuro.

\section{[palavras-chave]}

moda do futuro; tendências; cenários; narrativas.

[abstract] This article intends to develop a reflection on the anticipatory studies and future prospecting methodologies and their relationship with fashion, thought here as a means of expressing behaviors and consumption. These methodologies are: analysis of trends, construction of scenarios and creation of narratives. As an introduction of this discussion we will also analyze the relationship between fashion and time, discussing the possibilities of thinking about a future fashion.

[keywords] fashion; time; future; trends; scenarios; narratives. 


\section{Introdução}

A questão que dá título a este artigo poderia, à primeira vista, parecer tratar de um mesmo assunto, mas as formas como muitos estilistas, figurinistas, escritores e estudiosos da moda pensaram a moda do futuro não passaram pelas metodologias que foram desenvolvidas especialmente a partir da segunda metade do século XX, e que permitem discutir possiveis previsões e antecipações do futuro, de forma que a moda do futuro e o futuro da moda tornaram-se construções distintas.

A moda é descrita como a portadora do espírito de seu tempo (SOUZA, 1987), pois é uma das formas de dar materialidade a este por conter as tensões e disputas de cada época traduzidas em vestuário, acessórios e no próprio corpo. A moda, pensada sob essa perspectiva, não pode ser resumida apenas em uma linha do tempo, na qual, a cada século, década ou ano, uma imagem da moda corresponde a determinado intervalo temporal, deixando de fora tantas outras formas construídas pelos diversos grupos sociais nesse mesmo tempo.

Nessa visão, ao pensar a moda atribuída ao futuro, esta acabaria por ser mais uma reflexão sobre o presente do que uma possibilidade de criar novas expressões estéticas e simbólicas para uma sociedade cujas relações não são conhecidas $e_{\text {, }}$ portanto, não podem ser traduzidas pela moda.

A moda, porém, pode também ser pensada como catalisadora de sinais de mudança e entendida como lugar da iminência, captando novos comportamentos, da mesma forma como a arte, que, segundo Canclini (2014), possui essa qualidade, de tal forma que o futuro poderia ser pensado a partir da moda, pois esta é uma das componentes das narrativas criadas para a construção de uma visão de futuro, como veremos ao longo das discussões sobre algumas das metodologias utilizadas pelos estudos antecipatórios.

0 tempo da moda, a moda do futuro e o futuro da moda serão discutidos ao longo do artigo em duas etapas: a primeira focaliza a relação da moda com o tempo, a partir de uma revisão bibliográfica e da visão de estilistas; a segunda apresenta e discute três metodologias de prospecção e antecipação do futuro: análise de tendências, construção de cenários e criação de narrativas.

\section{A moda e o tempo}

Se cada período histórico se torna reconhecivel a partir das silhuetas que 0 definem, a moda, sob essa perspectiva, pode ser entendida como resultado do desenvolvimento da tecnologia, da economia, das relações sociais, da moral e das questões de gênero, enfim, resultado da ação humana em determinado tempo e local e, a partir do presente, podemos olhar para o passado e ter na moda uma forma de decifrar esse tempo. Segundo Gilda de Mello e Souza (1987),

[...] o julgamento da moda atual -como o de qualquer manifestação artística que se desenvolve sob nossas vistas - é provisório e depende de uma revisão futura, quando o afastamento no tempo, isentando-nos das coerções do momento, mostra-nos até onde a aceitação ou rejeição dos valores estéticos dependeu das condições sociais. (SOUZA, 1987, p. 23)

A moda é constituída por um acervo de formas, estilos, padrões, texturas e cores que reflete essa dinâmica social e será revisitado ao longo do tempo para ajudar a compor novas narrativas sobre o presente, como, por exemplo, as que se 
referem às questões de gênero, estratificação social, etárias, nacionais, religiosas, entre outras. 0 passado, entretanto, é visto a partir da perspectiva do presente, pois "a nossa compreensão da moda e do modo de vestir-se do passado, como do passado de uma maneira geral, é filtrada pelas nossas próprias preocupações e ideologias" (WILSON, 1985, p. 35).

É nesse sentido que podemos entender a afirmação de Anatole France:

Se, do amontoado de obras que serão publicadas cem anos depois da minha morte, eu tivesse a possibilidade de escolher uma, vocês sabem o que eu escolheria [...]. Dessa biblioteca do futuro eu não pegaria, não, um romance, nem um livro de história [...] simplesmente, meu amigo, eu pegaria uma revista de moda, para saber como as mulheres se vestirão um século depois da minha morte. $E$ tais vestidos me dariam mais informações sobre a humanidade futura do que todos os filósofos, os romancistas, os pregadores e os cientistas juntos. (FRANCE apud MALFITANO, 2008, p. 71)

Jornais e revistas de moda são essenciais para conhecer as relações sociais passadas, bem como as expressões do tempo presente e as sinalizações que a moda traz para as mudanças futuras das sociedades. Neles, o acervo da moda pode ser encontrado e lido como um arquivo dos embates entre o corpo e a sociedade ou captado como sinais de mudança.

0 poder do novo é um dos motores mais importantes da moda e o tempo do novo é o presente, pois não pode ser tradição (passado) nem possibilidade (futuro), a novidade é aqui e agora, o que faz com que o tempo primordial da moda seja o presente.

0 tempo mais notável da moda é, portanto, o presente, no qual se insere como produto e expressão simbólica das dinâmicas sociais. Ao se qualificar como efêmera, a moda necessariamente não pretende ser o lugar da tradição, nem durar para alcançar o futuro. A cultura industrial tem como tempo histórico o presente porque é uma cultura "sem rastro, sem futuro, sem prolongamento subjetivo importante, é feita para existir no presente vivo" (LIPOVETSKY, 2009, p. 244).

Já no século XX, Giacomo Leopardi, em Diálogo entre a moda e a morte (1982), apontava que a moda e a morte seriam irmãs, pois ambas são "filhas da Caducidade" (p. 20), ou seja, não haverá nada depois delas, seu tempo não inclui o futuro.

Essa relação entre lembrança e esquecimento é própria da moda, pois, segundo Svendsen, "a moda continua lembrando seu passado ao reciclá-lo, mas ao mesmo tempo esquece que ele é exatamente aquilo. E quanto mais depressa a moda evoluir, ao que parece, mais depressa esquecerá" (2010, p. 33).

Se a moda é essencialmente um novo recomeço constante e cada vez mais veloz, qual é a possibilidade de pensarmos a moda do futuro?

Determinar a moda do futuro é uma ambição não apenas dos estilistas, mas também está presente nos figurinos do gênero ficção científica. Ao apresentar ao público uma realidade distante no tempo, é necessário mostrar como esse futuro viria vestido. Primeiro na literatura e depois no cinema, os autores desse gênero de ficção criaram suas visões da moda a partir da realidade que imaginavam com 0 avançar do tempo.

No início do século $X X$, como herança do pensamento criado ao longo do século XIX, que atribuiu à ciência o papel central na construção das sociedades, a máquina passou a ser o grande paradigma de desenvolvimento e, em boa parte da ficção científica desse periodo, o humano deveria se aproximar desse ideal de eficiência. Para alguns desses autores, como aponta Elizabeth Wilson (1985), no futuro o corpo humano deveria inclusive desaparecer, e com ele a moda. 
Fruto desse mesmo ideal que supunha que a ciência e a tecnologia eram os grandes alicerces do progresso e, portanto, do futuro, foram os diversos manifestos criados pelos artistas do movimento futurista, que incluiam a moda nesse cenário.

[...] entre 1914 e 1933 produziram manifestos que abordaram especificamente a moda: o Manifesto Futurista do Traje Masculino (1913) e 0 Vestido Antineutro (1914), ambos escritos por Balla; 0 Manifesto Futurista da Moda feminina, escrito por Volt em 1920; 0 Manifesto Futurista da Gravata Italiana, dos autores Di Bosso e por Scurto e o Manifesto Futurista do chapéu italiano, de Marinetti, Monaschi, Prampolini e Somenzi foram escritos em 1933. (BORTULUCCE, 2011, p. 23)

No Manifesto Futurista da Moda Feminina, de Volt (1920), vemos que a visão do futuro da moda estava totalmente associada às novas tecnologias do período e às possibilidades que estas ofereciam às sociedades.

Idealizaremos na mulher as conquistas mais fascinantes da vida moderna. Teremos assim a mulher metralhadora, a mulher thanks-de-som. A senhora elegante será por nós transformada em um verdadeiro complexo plástico vivo. (VOLT, 1920 apud BORTULUCCE, 2011, p. 34)

Novos materiais, que substituiriam os tecidos convencionais na construção do vestuário, são destacados por Volt como parte do futuro da moda.

0 reino da seda deve terminar na história do vestuário feminino, assim como o reino do mármore está para desaparecer completamente nas construções arquitetônicas. 100 novos materiais revolucionários tumultuam na praça, implorando para ser admitidos na confecção dos vestidos das mulheres. Nós abriremos as portas dos ateliês de moda ao papel, ao papelão, ao vidro, ao papel laminado, ao alumínio, às cerâmicas esmaltadas, à borracha, à pele de peixe, ao tecido de embalagem, à estopa, ao cânhamo, ao gás, às plantas frescas e aos animais vivos. (VOLT, 1920 apud BORTULUCCE, 2011, p. 35)

A visão dos futuristas italianos enfatizava a ampliação das possibilidades do uso das novas tecnologias e de materiais para a moda, mas sua visão era ancorada na tecnologia de seu tempo. A moda deveria ser atualizada, em forma e matéria, pelos novos progressos científicos descritos a partir da realidade vivida por esses artistas.

Essa mesma relação pode ser vista nos figurinos de vários filmes de ficção cientifica, especialmente a partir da segunda metade do século XX, quando a Guerra Fria levou os embates entre as potências mundiais para o plano da superação tecnológica, muitas vezes reproduzindo imagens do passado e misturando seus elementos à estética do presente, construindo um futuro como idealização do passado e do presente.

Desde primeiras décadas do século XX, filmes de ficção científica vislumbram o futuro e suas possibilidades como temática. 0 gênero tornou-se durável e influente. Na construção cinematográfica 
deste temido e especulado futuro, pode-se criar um lugar inexistente e até improvável, que está por vir, e, assim, nunca projetado. Essa possibilidade surge de uma mistura de formas do passado, reinterpretando-as e misturando-as em novas combinações, que, por não seguirem linearidade temporal, não podendo ser um passado real e negando o presente, podem ser consideradas futuro. Estas considerações não estão isentas do momento da criação do filme, que entra no tempo representado, passado ou futuro, através de traços estéticos e ideológicos que indicam época e lugar em que o filme foi feito. (FORMIGA, 2012, p. 47)

0 futuro também foi pensado por alguns estilistas e, nos anos 1960, tivemos o surgimento do chamado estilo futurista na moda, que teve como maiores expoentes Paco Rabanne, André Courrèges e Pierre Cardin, cujas criações passaram a incorporar não apenas plástico e metais, materiais até então pouco usuais na moda, mas também algumas das transformações alcançadas pelos movimentos feministas do período, traduzidos, por exemplo, na minissaia, e que se tornaram imagens do futuro em filmes de ficção científica.

Barbarella é uma heroína espacial numa década em que a corrida espacial permeia o imaginário do homem $\mathrm{e}$, consequentemente, a moda. Ela apresenta o look espacial com cortes geométricos, cores invulgares e minissaia que se popularizou na época. A ligação com a moda do periodo não podia ser mais clara, já que Paco Rabanne criou boa parte de seus figurinos. Barbarella é fruto da liberação sexual, da luta pelos direitos das mulheres e das minorias e da experimentação com as drogas e ela vive tudo isso. A maturidade sexual por meio de roupas justas, a dominação por meio dos apliques de metal são alguns dos aspectos apresentados pelo figurino de Barbarella. (FORMIGA, 2012, pp. 101-102)

Ainda que nesse momento não fosse preocupação dos setores da moda no Brasil pensar uma moda do futuro, o jornal Folha da Manhã, de 7 de setembro de 1952, publicou uma matéria na qual vários criadores franceses respondem à questão Como será a moda no ano 2000?, e em diversas respostas vemos essa mesma relação entre materiais e tecnologia.

Qual será a moda feminina para o ano 2000? A "Revue de la Pansée Française" (sic) publica as opiniões dos mais famosos representantes daalta costura parisiense a esse respeito. Asopiniõessãoasmais autorizadas. Naturalmente, para profetizar no domínio da moda. Carven pensa na linha pura dos gregos: Por que a mulher do ano 2000 não se vestiria com os drapeados à antiga? Mas, ela modernizará o penteado em triangulo, fazendo uma verdadeira antena, capaz de captar as ondas hertziana, que permitiria às mulheres receberem mensagens enquanto andam pela rua. Prevê Carven a transformação dos panos livres do vestido em asas elétricas. Isso Ihes permitiria transportar-se sem necessidade do automóvel ou do avião. Seria a mulher "Radiovolante". (FOLHA DA MANHÃ, 7/9/1952)'

Já para um dos mais importantes nomes da moda dos anos 1950, Christian Dior, o futuro aparecia como uma volta radical ao passado, possivelmente fruto 
dos temores em relação a uma eventual destruição causada pelas bombas atômicas, uma vez que esse criador "vê a mulher do ano 2000 vestida de peles de animais. 0 que pode significar que Dior julga que a humanidade voltará à idade da pedra e os homens voltarão a viver nas grutas" (FOLHA DA MANHÃ, 7/9/1952).

A corrida espacial, empreendida entre a então União das Repúblicas Socialistas Soviéticas (URSS) e os Estados Unidos, mais enfaticamente entre os anos 1950 e 1960, também trazia para a moda visões de um mundo em que os deslocamentos seriam rápidos e as viagens espaciais comuns.

Jacques Griffe é de opinião que no ano 2000 se poderá almoçar em Nova York e jantar em Taiti; e as viagens à lua e aos demais planetas serão coisas comezinhas. Dai a idéia de um vestido de noite com calças, de tecidos especiais capazes de resistir aos efluvios terriveis da bomba atômica. (FOLHA DA MANHÃ, 7/9/1952)

Em outro trecho dessa matéria jornalística, temos a seguinte visão de Jacques Heim:

Impressionado com a pergunta, Jacques Heim criou um desenho de vestido determinado por duas tendencias principais: 0 desenvolvimento das ciencias eletronicas e nucleares permitirá a cada indivíduo enriquecer-se de orgãos ineditos de comunicação e de proteção; e não tendo o espirito mais em que pensar, homens e mulheres libertados, se entregarão às delicias da vida em sociedade. Por isso, o traje que Jacques Heim propõe para o ano 2000 é, ao mesmo tempo, cientifico e naturalista. Compõe-se de duas peças metalicas que servem de apoio ao tecido. A primeira, que ele chama de "capotone", coroa metalica vasia, de autodedução, na qual estarão colocados diversos aparelhos, tais como: "condensador de idéias", "cerebro-freio", "emissor de opiniões", "receptor telepatico", etc. A cabeleira será trançada verticalmente ao redor de uma antena vasia, que serve tambem de lampada para publicidade individual: radar detentor de sorriso e maquilagem luminosa, regulando o brilho do rosto. 0 traje - capa e saia - será de tecido "Hiroshima", naturalmente impermeavel às radiações atomicas. A capa cai num drapeado elegante; o "bottomographe", central eletronica que comporta à frente condicionamento de ar para o interior do vestuario, por raios infravermelhos; para a marcha e a natação, os pés serão guarnecidos com escamas reatoras a passo variavel e o corpo vestido de uma rede de pesca. (FOLHA DA MANHÃ, 7/9/1952)

0 último estilista a responder à questão foi Marcel Rochas, que assim definiu a sua visão da moda nos anos 2000:

Marcel Rochas pensa que a mulher do ano 2000 usará chapéu-antena. A bolsa será substituída por um aparelho de televisão e telefone portátil. Ele pensa que as palavras serão transmitidas, não pelos labios, mas pelas vibrações da garganta. A muIher será vestida com uma túnica à antiga, curta, com um véu. Permanecerá muito feminina, mas envolvida numa rede de antenas que lhes permitirão captar as novidades de todo o mundo. De acordo com essas opiniões autorizadas de mestres da alta 
costura, a maioria dos criadores de moda é de parecer que o vestuario das mulheres se adaptaria a todas as modernas. (FOLHA DA MANHÃ, 7/9/1952)

A moda do futuro, pensada por esses criadores, é resultado da leitura que fizeram do seu próprio tempo e das formas como interpretaram os desdobramentos possiveis a longo prazo desse presente.

Uma vez apontadas algumas das questões relativas à moda do futuro, a seguir, vamos discutir o futuro da moda a partir da perspectiva de três métodos de prospecção do futuro.

\section{Estudos antecipatórios}

Ainda que possamos dizer que o futuro sempre foi uma preocupação humana e muitas têm sido as formas de pensá-lo ao longo dos séculos, envolvendo predições e adivinhações, do ponto de vista das ciências humanas e sociais, seu estudo se estabelece com mais ênfase a partir da segunda metade do século XX.

As primeiras abordagens sobre os estudos prospectivos ocorrem após a Segunda Guerra Mundial, com a adoção do uso das técnicas que envolvem o desenvolvimento de cenários pela empresa norte-americana RAND Corporation, visando apoiar estratégias bélicas. Alguns autores referem-se ao trabalho pioneiro do filósofo e pedagogo francês Gaston Berger, considerado o primeiro a empregar a palavra prospectiva. Professor da Universidade de Aix-en-Provence, em 1957, ele fundou o Centre Universitaire International e o Centre de Prospective (em Paris), lançou um jornal com o mesmo nome e ainda o livro A atitude prospectiva (1958), no qual procurou diferenciar os conceitos de previsão, esta mais associada à profecia, em que ideia de futuro é construída à imagem do passado, e de prospectiva, na qual o futuro é decididamente diferente do passado, não sendo, portanto, possivel se pensar em um futuro único previsivel.

A atitude prospectiva não nos volta somente para o futuro. É preciso acrescentar que ela nos faz olhar longe. Em uma época na qual as causas engendram seus efeitos a uma velocidade que não cessa de crescer, não é mais possível considerar simplesmente os resultados imediatos das ações em curso. Nossa civilização é comparável a um carro que anda cada vez mais rápido em uma estrada desconhecida no meio da noite. Nesse caso, se quisermos evitar uma catástrofe, é preciso que os faróis do carro iluminem cada vez mais longe. Assim, a prospectiva é, essencialmente, o estudo do futuro distante. (BERGER, 2004, p. 313)

Ao longo do século $X X$, foram sendo desenvolvidas várias metodologias dedicadas aos estudos do futuro, não apenas visando uma previsão, mas também apresentando um caráter antecipatório, de maneira que pudesse efetivamente intervir nesse futuro.

Nesse quadro, a análise do comportamento dos consumidores permitiria a captação de sinais que identificariam não apenas ações imediatas como também de longo prazo e que possibilitariam pensar em cenários futuros para a produção de bens e serviços.

Da mesma forma, os objetos pensados a partir de sua materialidade e sua dinâmica estão inseridos em um contexto sociocultural e auxiliam na compreensão de seu tempo, e também apontam para as mudanças tanto do ponto de vista tecnológico quanto das relações sociais, razão pela qual a moda pode ser apontada como um importante veículo para essa observação. 
Assim, os estudos antecipatórios têm sido pensados, a partir das ciências sociais, como uma forma de entender as direções nas quais o corpo social se move e enfatiza que esses estudos têm que focar não apenas no desenvolvimento do conhecimento, mas também na sua comunicação, pois, quanto mais esse conhecimento se espraia, mais rapidamente se amplia.

A UNESCO (Organização das Nações Unidas para a Educação, a Ciência e a Cultura) tem reunido esforços para criar um projeto que consolide os estudos antecipatórios como disciplina.

0 objetivo principal do projeto é o desenvolvimento da Disciplina de Antecipação, incluindo o desenvolvimento de um sistema de estratégias e técnicas de antecipação. Quanto mais a cultura de antecipação se espalhar, mais fácil será desenvolver estratégias antecipatórias socialmente aceitáveis. Será então possível acumular experiência relevante em como pensar sobre o futuro e usar métodos de antecipação. Também será possivel tentar desenvolver uma linguagem e um conjunto de práticas que serão mais adaptados para pensar sobre o futuro e para o desenvolvimento de novas formas de abordar tópicos e oportunidades. (PROJECT ANTECIPATION, 2017, s.p., tradução nossa) ${ }^{2}$

Entre as metodologias de prospecção e antecipação, pretendemos destacar três: a identificação de tendências, a construção de cenários e a criação de narrativas, indicando sua relação com a moda a partir das transformações de comportamentos e do consumo, pois "conjugar os métodos tradicionais de previsão com novos métodos que permitam reagir com maior rapidez aos desejos dos consumidores é, hoje, um desafio para a maioria das marcas e dos criadores" (RECH, 2013, p. 4).

\section{Análise de tendências}

As tendências, em nossa sociedade, têm sido por longo tempo associadas à moda, e é nesse sentido que o senso comum as interpreta: aquilo que será eleito pelo gosto coletivo em termos de consumo. Ainda que não restritas à moda, as tendências têm nesta seu principal parâmetro: tendências estariam ligadas à troca rápida, característica da moda (LIPOVETSKY, 1989), e às formas de distinção e imitação (SIMMEL, 2008) e também seriam uma eficiente maneira engendrada pelo capitalismo para evitar tanto os riscos da superprodução quanto da ampliação da oferta em caráter constante (ERNER, 2015).

Saber as novas tendências, seja em moda, gastronomia, seja em turismo, confere ao usuário uma segurança em relação às suas escolhas. Ainda que as escolhas sejam individuais, elas estão sob o escrutínio do coletivo e, portanto, sujeitas à aprovação ou não. Dessa forma, escolher, já sabendo para onde tende o gosto coletivo, gera uma segurança em termos de julgamento, impedindo aquele que segue as tendências de correr riscos e estar sempre nos limites do aprovado.

Podemos caracterizar as tendências como previsões de curto prazo, que procuram detectar alterações que possam ser apresentadas como o novo, deixando para trás o já estabelecido. Segundo Caldas (2004, s.p.), "o conceito de tendência que se generalizou na sociedade contemporânea foi construído com base nas ideias de movimento, mudança, representação do futuro, evolução, e sobre critérios quantitativos". Ou, segundo Erner (2015), tendências poderiam ser descritas no âmbito sociológico, como "um comportamento adotado de maneira temporária por uma parte substancial de um grupo social quando esse comportamento é percebido como socialmente adequado para a época e situação" (ERNER, 2015, p.12). Ainda para esse autor, a sociologia das tendências 
buscaria dar uma resposta para a transformação do gosto coletivo, o que nos leva a perceber que o foco das tendências está nas alterações do gosto e no entendimento de como se propagam.

Cabe, então, discutir se a análise de tendências pode ser considerada prospecção quando se fala em pensar o futuro.

Segundo Berger (2004, p. 313), "as previsões têm mais chance de serem exatas quando elas abrangem um período longo, ao invés de um período curto". Isso se dá em função de que os estudos verdadeiramente antecipatórios não trabaIham com certezas, mas com possibilidades e precisam acompanhar um determinado fenômeno ao longo do tempo a fim de verificar a sua real implementação. As previsões de curto prazo precisam ser mais exatas e peremptórias, de modo que elas não chegam a ser um estudo de fatos e ações que, em conjunto, podem mudar a sociedade em um tempo e lugar; as previsões aparecem quase como determinações, que deixam ao usuário a escolha de aderir ou não a elas, mas retira do conjunto dos agentes sociais a real construção dessa tendência.

Nenhum setor supera a moda em relação a transformar em certezas algo que deveria ser, por definição, incerto - ao instrumentalizar o conceito de tendência como uma ferramenta para a produção, criando um sentido de afirmação ao que era proposta, transformando em decreto suas previsões.

As tendências surgem dentro da indústria da moda, considerando os criadores e produtores, e disseminam-se pela mídia por meio dos editores e jornalistas de

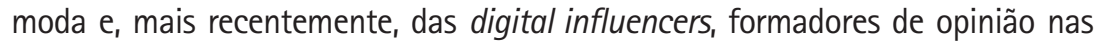
redes sociais. A cada estação, cores, estampas e modelagens são eleitas como tendências, mas, ao se consolidar essa eleição, elas já são uma realidade e não mais apenas uma possibilidade.

Como afirma Guillaume Erner (2015), as tendências podem ser consideradas uma profecia autorrealizável, pois não dependem de um conjunto complexo de mudanças sociais, como ocorre nas projeções de longo prazo, mas apenas da adesão dos consumidores. Tendência aparece como um adjetivo, significando algo que está muito em voga (CALDAS, 2004). "Como oráculos, as revistas lançam ordens da mesma maneira que os papas lançam bulas. As leitoras são interpeladas com expressões como 'você precisa', 'você tem' e outras variações sobre o tema "must have" (ERNER, 2015, p. 58). Nesse sentido, a tendência é vista como uma confirmação daquilo que já aconteceu e que se projeta como uma antecipação.

Entretanto, não podemos deixar de considerar que mudanças de longo alcance, transformações de padrões de comportamento e de consumo, também podem e são alcançadas pela moda, o que acontece é que, quando elas se tornam suficientemente visiveis na sociedade, acabam sendo incorporadas pela indústria da moda e, aí sim, dentro da lógica da moda, viram tendências.

Um dos exemplos mais recentes pode ser identificado na moda surgida a partir do movimento hip hop, que emergiu de uma mudança nas periferias dos grandes centros urbanos do Ocidente, criando uma visualidade que corresponde à tal mudança e que, uma vez consolidada como expressão da identidade desses grupos, deixou de ser apenas o estilo de seus agentes e se transformou em tendência de moda, ou seja, em moda.

A moda é, dessa forma, um lugar no qual podemos perceber as transformações em curso na sociedade, porém, não é o mecanismo de criação de tendências de moda, mas uma forma de captar os sinais dessa transformação. A moda, assim como a arte, pode ser vista como um lugar de iminência (CANCLINI, 2014), no qual as mudanças em curso nas sociedades estão se agrupando e emitindo sinais de que algo diferente do estabelecido está para acontecer. Para Canclini (2014), dizer que a arte está situada na iminência significa que ela não apenas suspende a realidade, mas está situada no momento anterior ao qual o real é uma possibilidade, quando 
os fatos podem ser tratados como eventos que estão prestes a vir a ser. Nesse sentido, não pode ser compreendida apenas como tendência, mas sim como mecanismo de captação das mudanças e deve ser lida como um emissor de sinais de algo que poderá se traduzir em futuro.

\section{Construção de cenários}

A segunda metodologia de prospecção de futuro que vamos discutir é a chamada construção de cenários. 0 uso do termo cenário, segundo Cavalheiro e Fellows Filho (2011), teria sido sugerido por Leo Rosten, sociólogo, escritor, roteirista e assessor da RAND Corporation no fim dos anos 1940. Ao observar um grupo de físicos que tentavam achar um nome adequado para as descrições alternativas de como os satélites poderiam se comportar, disse: "Vocês deveriam chamá-las de cenários. Nos filmes, cenário é o esboço minucioso de um futuro filme" (CAVALHEIRO, FELLOWS FILHO, 2011, p.11). A concepção de cenários pressupunha a ideia de compreender o quadro fictício para o qual se buscava uma resolução. Em seguida, essa ideia passou a ser difundida para outras áreas do conhecimento, tendo nos Estados Unidos e na França os principais centros de desenvolvimento de técnicas de construção de cenários.

A partir da década de 1960, os estudos de construção de cenários se ampliam e governos e empresas passam a utilizar essa abordagem e a desenvolver métodos específicos para dar suporte a processos de planejamento estratégico e tomadas de decisão. Entre os exemplos mais conhecidos está o da empresa de petróleo Shell que, a partir de estudos prospectivos realizados em 1969, antecipando a elevação dos preços do petróleo em 1973, iniciou o processo de extração no Mar do Norte antes dos demais concorrentes.

Existem várias definições para cenários assim como há uma grande variedade de métodos úteis para a sua construção. Entretanto, o conceito central de que cenários compreendem uma sequência de eventos que, emergindo do presente, podem conduzir ao futuro (MASINI, 2000) está presente em qualquer definição e serve de base para as mais variadas metodologias. Na forma mais frequentemente utilizada, o cenário elaborado revela um futuro possivel e explicita uma sequência de condições, mudanças ou eventos necessários para alcançá-Io. (CAVALHEIRO; FELLOWS FILHO, 2011, p. 5)

Em 1972, foi fundado o Clube de Roma, cujo trabalho Os limites do crescimento (1972) marca a utilização dos estudos prospectivos e da construção de cenários como estratégia para políticas públicas de ampla escala. Vários autores têm se dedicado aos estudos prospectivos e de criação de cenários ao longo das últimas duas décadas do século XX e início do século XXI e entre eles destacam-se Peter Schwartz, Michel Godet e Eleonora Masini.

Consolidada como método para entendimento dos rumos da sociedade, a construção de cenários se pauta por vários sinais, de maior ou menor magnitude, envolvendo uma perspectiva global ao lado do planejamento local.

Dessa forma, os cenários não podem ser entendidos como formas de se prever o futuro, mas como instrumento para se pensar os possiveis futuros a partir do presente levando em conta também o passado. Os cenários são elaborados como campo de batalha das transformações, avaliando o peso que cada um dos componentes pode apresentar e como o todo vai se comportar a partir de cada uma das composições possiveis de serem pensadas.

Tomemos como exemplo os cenários sobre o futuro da mobilidade urbana que são construídos atualmente: a moda também deve olhar para eles e ser capaz de 
pensar em respostas para as perspectivas que esses cenários criam. Dessa forma, as possibilidades que vemos hoje em termos de ações para a mobilidade urbana são de compartilhamento, uso de aplicativos, como o Uber, aumento do uso das ciclovias, aumento do número de pedestres e de consumo pensado em escala humana, incrementando o consumo em base territorialmente próxima, ao serem colocadas em confronto com o aumento do uso do automóvel, ampliação das distâncias para o consumo e queda no uso do transporte público, entre outros comportamentos contrários que são lançados nos cenários para efeito de ponderação. A indústria da moda tem que saber avaliar cada uma dessas possibilidades e pensar estratégias para o futuro, seja em termos de tecnologias têxteis, seja em termos dos estilos e das modelagens.

Esse tipo de estudo, de fato, se apresenta com um grau de prospecção e projeção muito maior do que a análise de tendências, quando se quer pensar um futuro de longo prazo.

Uma versão dessa metodologia tem sido empregada não apenas no âmbito das empresas e nas previsões de caráter econômico, mas em situações de transformação política e social. Essa metodologia é a do Planejamento de Cenários Transformadores e foi utilizada, nos anos 1990, na África do Sul para conduzir o processo de mudanças que o fim do regime de apartheid acarretaria. Segundo Adam Kahane, essa metodologia tem como propósito "permitir àqueles que estão tentando mudar o futuro de maneira colaborativa, transformar, em vez de se adaptar à situação em que se encontram" (KAHANE, 2013, p. 23).

A expectativa dessa metodologia não é apenas entender as possiveis configurações do futuro, mas efetivamente planejar esse futuro. Esse tem sido o sentido mais fecundo dos estudos sobre o futuro, a premissa de que, ao enxergarmos seus caminhos, podemos aspirar a transformá-lo.

É possivel pensar que os caminhos da moda podem ser tidos como formas de alterar comportamentos a partir de ações que já estão visiveis no presente, tais como o menor desperdício de matérias-primas, menor uso da moda como fonte de exclusão, compartilhamento e cocriação. Enfim, várias correntes são percebidas atualmente e podem ser vistas como opção para investirmos na criação de um futuro melhor por meio da moda se optarmos por transformar esses sinais em objetivos.

\section{Criação de narrativas}

As discussões nas ciências sociais sobre os estudos antecipatórios partem também da ideia de que o futuro é um fato cultural e que a capacidade de aspirar a ele seria a noção que uniria a cultura, a voz e o futuro; voz entendida como habilidade de se fazer representar (APPADURAI, 2013). No sentido proposto por Appadurai, a cultura é a grande narrativa que integra esses elementos, de modo que podemos não ser capazes de controlar o que o futuro será, mas existiriam muitas maneiras de pensar sobre os caminhos que gostariamos que fosse. Para esse autor, devemos "lançar os fundamentos de uma antropologia do futuro [...] que podem ajudar na vitória de uma política de possibilidade em vez de uma política de probabilidade" (APPADURAl, 2013, p. 3, tradução nossa) ${ }^{3}$.

A cultura digital, especialmente em seus aspectos referentes às redes sociais, e seus novos fluxos de criação e participação na construção da cultura contemporânea, também pode ser descrita como uma porta de percepção dos novos rumos da sociedade. Com essas ferramentas, temos quase que uma lupa apontada para os indivíduos, descobrindo seus comportamentos, gostos e estilos de vida a partir de sua participação nas redes sociais e em outros mecanismos digitais - com isso é possível acompanhar de forma muito mais acurada as movimentações sociais em direção às mudanças.

Agregar essas ferramentas, criando novas formas de pensar o futuro a partir do consumo, dos estilos de vida e da cultura material, pode nos ajudar a estabelecer propostas para o desenvolvimento futuro da moda. 
A ideia de construir narrativas amplia a ideia de cenários, já que as narrativas podem tomar caminhos diversos e ir além dos limites propostos nos cenários. As narrativas podem ser consideradas um modo de pensar, uma forma de organização dos conhecimentos e experiências, de maneira que possam ser compartilhadas com o propósito de "domesticação do novo para torná-lo familiar" (EMILIANI, 2009, p.159). A narrativa não é uma explicação dos fatos, mas uma interpretação.

Um dos pontos que temos que levar em consideração quando pensamos a estratégia das narrativas é o do surgimento de termos específicos para designar novos comportamentos. Em seu trabalho sobre o surgimento do trabalho de cuidador, Nadya Araujo Guimarães (2014) chama a atenção para a novidade que é o emprego desse termo, pois, até recentemente, os cuidados com os idosos eram atribuição da família. Ao acompanhar no espaço público as palavras "cuidador" e "cuidadora" - espaço público considerado pela pesquisadora como a imprensa -, a frequência com que elas aparecem ao longo dos últimos anos permite perceber a mudança de um comportamento: o de delegar a profissionais o cuidado com algum familiar incapacitado de viver com autonomia.

A trajetória das formas de nomear se constitui numa pista instigante por meio da qual podemos acompanhar como processos sociais se constituem. Palavras surgem e se consagram no uso social corrente ou redefinem os conteúdos a que aludem, num movimento que deixa, para nós interpretes, as pegadas preciosas das transformações sociais em curso: novas modalidades de organização da vida, novos papéis, novas formas de divisão do trabalho, novos atores, novas representações. (GUIMARÃES, 2014, p. 3)

A moda pode ser apontada como um dos campos em que novas palavras surgem com grande constância para designar novos estilos, cores ou mudanças efetivas de comportamento que se consolidam em novas formas de viver.

Por ser especialmente uma atividade social, a moda permite o estudo de seus produtos culturalmente significativos e de seus integrantes (aqueles que participam das atividades ligadas à moda). Ademais, a isso se acrescenta também o exame de seu léxico, marcado por movimentos de expansão, atualização e modificação, com fundamento nos processos disponibilizados na língua comum. (ORSI; CARMO, 2015, p. 66)

Novos termos como gender bender, agender e outros que procuram discutir uma possivel mudança entre as representações de gênero têm aparecido com frequência na moda nos últimos anos e, por meio deles, podemos perceber que há um comportamento de consumo se alterando, reflexo de um novo posicionamento dos gêneros. Esse é um exemplo de termos que constituem novas narrativas sobre a moda.

Como aponta Howard Becker (2007), os fatos só existem em função das ideias que usamos para descrevê-los, razão pela qual a redação científica também é uma narrativa que aponta para mudanças futuras, pois, segundo o autor,

[...] ao contrário das tendências, que não podem ser percebidas em seu processo, nas narrativas, cada etapa é construída por motivos reais que fazem as pessoas escolherem caminhos: as relações pessoais, com o mundo, com o trabalho, as novidades tecnológicas, os sonhos, a consciência, a motivação do outro, a ambição, enfim, são 
tantas as razões para escolhas que visam um determinado futuro que, em conjunto, apresentam também uma variedade de futuros possiveis. (BECKER, 2007, s.p.)

As ações humanas não acontecem sem que estejam em um processo, considerando que há um grande número de passos seguintes possíveis, mas, como aponta Becker (2007), esses passos não são infinitos e apenas um número pequeno pode ser considerado mais ou menos provável, pois eles estão em uma cadeia de contingência, ou seja, uns em dependência dos outros. As variações da moda que refletem as transformações sociais quase sempre não são mudanças aleatórias ou rupturas radicais, mas mostram esse encadeamento de eventos, como podemos perceber na pesquisa de Diana Crane (2006) sobre o uso da calça pelas mulheres, processo que levou cerca de um século para se completar, pois estava diretamente associado às mudanças do papel social feminino.

A narrativa do uso das calças pelas mulheres pode ser vista como uma trajetória para a emancipação feminina e, se olhada a partir da segunda metade do século XIX, aponta para um futuro com a maior participação feminina no mundo do trabalho e na vida pública, ao menos no Ocidente, onde o uso das calças femininas se consolidou a partir de meados do século XX.

Dessa forma, podemos perceber que os eventos não são nem aleatórios nem determinados (BECKER, 2007), mas estão em uma cadeia sucessiva de acontecimentos interconectados e partem de escolhas que fazem sentido dentro da narrativa que estamos analisando, mesmo não tendo sido as melhores escolhas. Ainda segundo Becker (2007), as palavras que usamos para pensar as narrativas são: causalidade, dependência e conexão. São termos indicativos de variação e que apontam para possíveis resultados, não para um resultado único e inexorável, já que as atividades humanas não seguem padrões, mas, pelo contrário, são sempre variáveis e inesperadas. Por isso, conseguem criar narrativas que estarão sempre em construção, pois as mudanças na vida social são sempre esperadas e desejadas, e o que pretendemos enxergar não é apenas a mudança imediata em si, mas a direção que ela toma e que irá construir um futuro diferente.

\section{Considerações finais}

0 futuro sempre foi uma questão para a moda, porém, era visto como algo idealizado a partir do presente, como vimos no início deste artigo, ou era construído com base nos agentes do campo e transformado em tendências, as quais não representariam uma visão a longo prazo. As transformações que a moda pode engendrar são resultado dos embates no plano da cultura e do social e tornam visíveis essas alterações.

Como vimos, as ações dos agentes do campo da moda estão mais preocupadas com o presente e ainda não têm como objetivo, de forma consistente, antecipar o futuro e agir sobre ele. No âmbito da sociedade, entretanto, cada vez mais, observamos forças que se movem em direção ao futuro se expressando também por meio da moda e, nesse sentido, podemos construir cenários e narrativas para prospectar as mudanças que tenham na moda um vetor das transformações que desejamos, tanto no comportamento quanto no consumo.

Cabe lembrar, entretanto, que as projeções para o futuro são um campo de incerteza e possibilidades e, por essa razão, sujeitos a desvios e a eventos imponderáveis que podem alterar as perspectivas projetadas. Por isso, os estudos antecipatórios entendem as previsões como possibilidades, e não como certezas.

Uma das grandes dificuldades desses estudos é acompanhar as previsões e confrontá-las com os eventos que se efetivaram. Muitas previsões são feitas diariamente, mas não costumamos voltar a elas e conferir o grau de acerto, especialmente quando projetamos mudanças de comportamento. 
Nesse sentido, o que podemos fazer é efetivamente planejar e antecipar um futuro para a moda que seja compatível com o futuro que desejamos para a sociedade, e que tenha na moda uma de suas forças motoras. Para tanto, é preciso entender as metodologias que compõem os estudos antecipatórios e como podemos utilizá-las e aperfeiçoá-las para projetar o futuro da moda.

\author{
Recebido em: 06/02/2017 \\ Aprovado em: 03/03/2017
}

\title{
NOTAS
}

${ }^{1}$ Optou-se por transcrever as citações deste texto com a grafia original da época de sua publicação.

2 "The project's main objective is the development of the Discipline of Anticipation, including the development of a system of anticipatory strategies and techniques. The more the culture of anticipation spreads, the easier it will be to develop socially acceptable anticipatory strategies. It will then be possible to accumulate relevant experience on how to think about the future and to use anticipatory methods. It will also be possible to try and develop a language and a body of practices that are more adapted for thinking about the future and for developing new ways to address threads and opportunities." (PROJECT ANTECIPATION, 2017, s.p.)

3 "Lay the foundations of an anthropology of the future [...] that can assist in the victory of a politics of possibility over a politics of probability." (APPADURAI, 2013, p. 3)

\section{REFERÊNCIAS}

APPADURAI, Arjun. The future as cultural fact: essays on the global condition. London, New York: Verso, 2013.

BECKER, Harold. Segredos e truques da pesquisa. Rio de Janeiro: Jorge Zahar Ed., 2007. [Kindle edition]

BERGER, Gaston. A atitude prospectiva. In: Parcerias Estratégicas, n. 19, dez. 2004. Disponivel em:<http:/l seer.cgee.org.br/index.php/parcerias_estrategicas/article/viewFile/249/243>. Acesso em: 20 maio 2016.

BORTULUCCE, Vanessa Beatriz. 0 manifesto futurista da moda feminina. In: lara: Revista de Moda, Cultura e Arte. São Paulo: vol. 4, n. 2, dez. 2011, pp. 20-35. Disponivel em: <http://www1.sp.senac.br/hotsites/blogs/ revistaiara/wp-content/uploads/2015/01/03_IARA_vol4_n2_Dossie.pdf

CALDAS, Dario. Observatório de sinais: teoria e prática da pesquisa de tendências. E-Odes, 2015. [Kindle edition]

CANCLINI, Néstor Garcia. Art beyond itself: anthropology for a society without a story line. Duke University Press, 2014.

CAVALHEIRO, Esper; FELLOWS FILHO, Lelio. Cenários futuros: uma aplicação na área de biotecnológica. In: Future Studies Research Journal. São Paulo, v. 3, n. 1, p. 2-13, jan/jul, 2011.

CRANE, Diana. Moda e seu papel social: classe, gênero e identidade das roupas. São Paulo: Editora Senac São Paulo, 2006.

EMILIANI, Francesca. A realidade das pequenas coisas: a psicologia do cotidiano. São Paulo: Editora Senac São Paulo, 2009.

ERNER, Guillaume. Sociologia das tendências. São Paulo: Gustavo Gili, 2015.

FOLHA DA MANHÃ. A moda no ano 2000. In: Folha da Manhã, 7 de setembro de 1952. Disponivel em: $<$ <ttp://almanaque.folha.uol.com.br/moda_07set1952.htm>. Acesso em: 15 dez. 2016.

FORMIGA, Bárbara Gomes. Futuro do presente: observação de comunalidades estético-visuais entre figurinos de filmes futuristas e a moda vigente. Dissertação de mestrado apresentada no Programa de Pós-Graduação em Design da Universidade Federal de Pernambuco, 2012. Disponivel em:<http://www. repositorio.ufpe.br/handle/123456789/11430>. Acesso em: 20 jan. 2017. 
GUIMARÃES, Nadya Araujo. Casa e mercado, amor e trabalho, natureza e profissão: controvérsias sobre o processo de mercantilização do trabalho de cuidado. In: Cadernos Pagu. Campinas, n. 46, pp. 59-77, abr. 2014. Disponivel em: <http://www.scielo.br/scielo.php?script=sci_arttextttpid=S010483332016000100059\&tlng=en\&tnrm=iso>. Acesso em: 27 maio 2016.

KAHANE, Adam. Planejamento de cenários transformadores: trabalhando juntos para mudar o futuro. São Paulo: Editora Senac São Paulo, 2013.

LEOPARDI, Giacomo. Operette morali: essays and dialogues. Califórnia: University of California Press, 1982. Disponivel em: <https://archive.org/details/essaysanddialog00leopgoog>. Acesso em: 24 maio 2017

LIPOVETSKY, Gilles. 0 império do efêmero: a moda e seu destino nas sociedades modernas. São Paulo: Companhia das Letras, 2009.

MALFITANO, Alberto. 0 jornalismo de moda: aplicações no campo histórico. In: SORCINELL, Paolo (org.) Estudar a moda: corpos, vestuários, estratégias. São Paulo: Editora Senac São Paulo, 2008.

ORSI, Vivian e CARMO, Leonardo. Itens lexicais neológicos e a moda: um estudo ilustrativo da revista L'Officiel Brasil. in: lara: Revista de Moda, Cultura e Arte, vol. 8, n. 1, abr. 2015. Disponivel em: <http:// www1.sp.senac.br/hotsites/blogs/revistaiara/wpcontent/uploads/2015/04/63_lara_artigo_ed-vol-8-n-1ano-2015.pdfs.Acesso em: 25 maio 2016.

PROJECT ANTECIPATION. The Project. Disponivel em: <http://www.projectanticipation.org/index. ph?option=com_contentEtview=articlectid=3cttemid=472>. Acesso em: 18 abr. 2016.

$\mathrm{RECH}$, Sandra. Estudos do futuro: uma contribuição para a indústria da moda. In: Anais do $9^{\circ}$ Colóquio de Moda, Fortaleza, 2013. Disponivel em: <http://www.coloquiomoda.com.br/anais/anais/9-Coloquio-deModa_2013/ARTIGOS-DE-GT/Artigo-GT-Design-e-Processos-de-Producao-em-Moda/Estudos-do-Futurouma-contribuicao-para-a-ind\%C3\%BAstria-da-moda.pdf $>$. Acesso em: 17 jan. 2017.

SIMMEL, Georg. A moda. In: lara: Revista de Moda, Cultura e Arte. São Paulo, vol.1, n.1, abr/ago 2008. Disponivel em:<http://www1.sp.senac.br/hotsites/blogs/revistaiara/wp-content/uploads/2015/01/07 IARA_Simmel_versao-final.pdfs. Acesso em: 16 maio 2016.

SOUZA, Gilda de Mello e. 0 espírito das roupas: a moda no século XIX. São Paulo: Companhia das Letras, 1987

SVENDSEN, Lars. Moda: uma filosofia. Rio de Janeiro: Zahar, 2010.

WILSON, Elizabeth. Enfeitada de sonhos: moda e modernidade. Rio de Janeiro, Edições 70, 1985. 